\title{
Phenomenological Models and Peculiarities of Evaluating Fatigue Life of Aluminum Alloys Subjected to Dynamic Non-Equilibrium Processes
}

\author{
Mykola Chausov ${ }^{1}$, Andrii Pylypenko ${ }^{1}$, Pavlo Maruschak ${ }^{2, *(1)}$ and Abdellah Menou ${ }^{3}$ \\ 1 Department of Mechanics, National University of Life and Environmental Sciences of Ukraine, \\ Heroiv Oborony Str. 15, 03041 Kyiv, Ukraine; m.g.chausov@gmail.com (M.C.); andriy3pl@gmail.com (A.P.) \\ 2 Department of Industrial Automation, Ternopil National Ivan Puluj Technical University, \\ Rus'ka Str. 56, 46001 Ternopil, Ukraine \\ 3 Moroccan Airports Authority, Mohammed V International Airport, Nouaceur, \\ Casablanca 8101, Morocco; a.Menou@onda.ma \\ * Correspondence: Maruschak.tu.edu@gmail.com; Tel.: +38-097-407-2696
}

Citation: Chausov, M.; Pylypenko,

A.; Maruschak, P.; Menou, A.

Phenomenological Models and

Peculiarities of Evaluating Fatigue Life of Aluminum Alloys Subjected to Dynamic Non-Equilibrium Processes. Metals 2021, 11, 1625. https:// doi.org/10.3390/met11101625

Academic Editor: Denis Benasciutti

Received: 8 September 2021

Accepted: 11 October 2021

Published: 13 October 2021

Publisher's Note: MDPI stays neutral with regard to jurisdictional claims in published maps and institutional affiliations.

Copyright: (c) 2021 by the authors. Licensee MDPI, Basel, Switzerland. This article is an open access article distributed under the terms and conditions of the Creative Commons Attribution (CC BY) license (https:// creativecommons.org/licenses/by/ $4.0 /)$.

\begin{abstract}
Physical-mechanical models for predicting the fatigue life of aluminum alloys D16ChATW and 2024-T351 are proposed and tested. Damage accumulation patterns are established for these alloys in the initial state and after dynamic non-equilibrium processes (DNP) of different intensity that occur at maximum cycle stresses $\sigma_{\max }$ from 340 to $440 \mathrm{MPa}$, cycle asymmetry coefficients $R=0.1$ and load frequency $f=110 \mathrm{~Hz}$. The main model parameters are the initial alloy hardness $H V$ and the limiting parameters of scatter of hardness values $\mathrm{m}$. These parameters are evaluated in the process of cyclic loading with fixed maximum stresses of the cycles. Relative values me are also considered. For the alloys in the initial state, the proposed models are shown to be in good agreement with the experimental results. Conversely, structural changes taking place in alloys after DNP complicate the prediction of their fatigue life.
\end{abstract}

Keywords: aviation aluminum alloys; fatigue life; dynamic non-equilibrium processes (DNP); forecasting fatigue life

\section{Introduction}

Aluminum alloys of transportation systems can be subjected to various types of shortterm overloads during operation. These overloads are caused by changes in operating conditions and the influence of wind, wave and other factors [1-4]. The plastic deformation of alloys that occurs under such loading conditions at different structural and scale levels definitely affects the damage accumulation kinetics during cyclic deformation and, accordingly, the cyclic durability of structures [4,5]. Particularly dangerous are short-term overloads of significant amplitude, which have certain similarities to dynamic non-equilibrium processes [6]. Their consequences may include early fracture of structural elements and components.

Dynamic non-equilibrium processes (DNPs) are associated with an intense exchange of energy between individual elements of a statically indeterminate structure and features of some parameters of the mechanical system. The DNP activates the extreme dissipative processes associated with the self-organization of the microstructure. The term "self-organization" has been a generally accepted term since the middle of the twentieth century. It was introduced in the works of Haken, Ebeling, Nicolis and Prigogine and determines the possibility of a well-ordered structure being formed in thermodynamic systems with conditions far from equilibrium. In solid-state physics, it means the possibility of formation of a well-ordered defect structure that promotes hydrodynamic plastic flow failing the dislocation slide, that is, it reduces to hydrodynamic plastic flow instead of dislocation slide. In the general case, self-organization of the material of the mechanical 
system arises due to the need for additional dissipation of energy acquired due to external influences. Under such conditions, self-organization intensifies the mechanism of energy transfer through the material of the samples. Finally, DNP significantly changes the initial mechanical properties of structural alloys and the structure of their surface layers.

Therefore, investigations into the impact of such processes and the description of their phenomenological and statistical features will take into account the above phenomena $[7,8]$. However, the effect of dynamic non-equilibrium processes (DNPs) is understudied at present, because, as a rule, it does not cause sudden fracture, but has a cumulative effect, which decreases the overall cyclic durability of the structure $[9,10]$. In fact, this effect is usually added to the effect of cyclic deformation and is not studied separately [11]. This approach is simplistic and does not always give good results.

It is noteworthy that the DNP activates additional plastic deformations in the material, leading to changes in its ultimate plasticity. This effect may be positive, providing for a significant plasticization of the material without compromising its strength [12]. Under cyclic deformation, this causes the extension of cyclic durability $[13,14]$.

Therefore, a reliable evaluation of the fatigue life of aluminum alloys depending on operating conditions is an important task. There are many different approaches to solving this problem [1-4,15], including purely phenomenological models [16,17], approaches based on the changes in the alloy surface relief [18,19], FEM analysis, i.e., the approach based on the number of defects in the surface layers estimated during photography [20-22], etc. Despite a significant number of works dedicated to this problem, appreciable progress in the reliable prediction of the fatigue life of aluminum alloys of different classes has not been made. This is because, in assessing the fatigue life of aluminum alloys, the major factor is the choice of parameters that characterize the degree of damage to the surface layers of alloys and the algorithm for predicting long-term structural strength under variable loads taking into account current damage [23-25]. However, given the wide range of real operational cyclic loads, to which structures are subjected, choosing such parameters is very problematic $[25,26]$.

We emphasize that the parameter, the variation of which can characterize the degree of alloy degradation, should be based on such physical and mechanical characteristics, the measurement of which gives an integral characteristic of the condition of the surface layers' structure. Therefore, of particular importance are the methods that allow a non-destructive testing of the material surface layer to be conducted. These are primarily the methods for assessing the surface layer's condition by its hardness, which can be measured by many methods that differ in the indenter's shape, loading conditions and load application mode $[27,28]$. They also differ in the speed of interaction between contacting bodies, as well as the duration of interaction. Many of these methods are standardized. To date, an original approach to predicting the fatigue life of structural materials is being developed, which was proposed by Y. Murakami $[29,30]$.

This approach is as follows: to predict the fatigue limit of materials in cyclic tests, Y. Murakami proposed using the initial hardness of materials and the critical defective area in the surface layers of materials as basic parameters. The original version of this formula is as follows:

$$
\sigma_{f,-1}=C_{1} \frac{H V+C_{2}}{\sqrt{\text { area }}^{\frac{1}{6}}}
$$

where $H V$ is the initial hardness according to the Vickers method, the $C_{1}$ coefficient is 1.43 for surface defects and 1.56 for subsurface defects and the $C_{2}$ coefficient is 120 for a wide class of materials.

In the years that followed, researchers have time and again modified this formula for different cases of cyclic loading, including at different cycle asymmetry coefficients [31-33]. The main difficulty in using this approach is the need for continuous monitoring of the area with defects located in a particular section of the specimen or structural element. One should also know the critical area of surface defects under different types of variable loads. Therefore, choosing the damage parameter in the form of an area with defects in the surface 
layers of materials requires special fixation techniques. Moreover, numerous experimental studies are also required to find out the accumulation patterns of surface defects of different shapes and intensities depending on different conditions of cyclic loading.

On the other hand, large-scale studies conducted at the G.S. Pisarenko Institute for Problems of Strength of the National Academy of Sciences of Ukraine under the leadership of A.O. Lebedev showed that the parameters, which are most sensitive to many types of structural transformations in the surface layers of materials, were derived from the absolute values of the material hardness. Tests were performed on the same specimens under identical conditions. Therefore, an idea of estimating the material damage by scattering the absolute values of hardness appeared. One of such parameters is the homogeneity (uniformity) of the material structure, the definition of which is the basis of the LM-hardness method developed at the G.S. Pisarenko Institute for Problems of Strength of the National Academy of Sciences of Ukraine [34,35]. The method is standardized in Ukraine [36].

The objective of this research project is to study and systematize the effect of the DNP on the cyclic durability of aluminum alloys and to create a phenomenological model to describe these processes.

\section{Materials and Methods of Research}

\subsection{Methods of Mechanical Tests}

In this paper, experimental results of fatigue tests on specimens from sheet industrial aluminum alloys D16ChATW and 2024-T351 are analyzed [13,14]. All studies on DNP realization in aluminum alloys due to impact-oscillatory loading of different intensities were conducted on an upgraded test machine, ZD-100Pu (WPM, Leipzig, Germany). The main methodological aspects of this technique are described in detail in [37-39]. Relevant studies to assess the fatigue life of aluminum alloys in the initial state and after DNPs of different intensities conducted on a resonant test machine Rumul Testronic (Russenberger Prüfmaschinen AG, Rundbuck, Neuhausen am Rheinfall, Switzerland) 50kN at identical variable loads applied at room temperature are described in $[13,14]$. Specimens from D16ChATW and 2024-T351 alloys in different states were tested under the following conditions: soft loading mode; stress ratio $R=0.1$; load frequency of $110 \mathrm{~Hz}$; maximum dynamic stress $\sigma_{\max }$ of $440,400,370$ and $340 \mathrm{MPa}$.

The intensity of introducing impulse energy into the alloys was controlled by sudden increments of dynamic deformation $\varepsilon_{i m p}$ during the realization of DNP. The simplicity and advantages of this procedure have been time and again noted in [12-14]. In addition, this procedure makes it possible to easily assess the effect caused by the intensity of introducing impulse energy on the fatigue life of the alloy at a given variable load $[13,14]$.

\subsection{Evaluation Methods of Physical-Mechanical Properties of Surface Layers of Aluminum Alloys}

The hardness of the surface layers of alloys in the initial state and those subjected to the specified variable loading conditions, in particular, DNPs of different intensities, was measured on a hardness tester NRO-10 by the Vickers method at a working load of $0.456 \mathrm{~kg}$. The number of indentations for each investigated area of the specimen surface was no less than 30. The authors of [36] took the Weibull homogeneity coefficient calculated by the Gumbel formula [36] as a parameter that characterizes scatter of hardness values [36]:

$$
m=0.4343 d_{n}\left[\frac{l}{n-l} \sum_{i=1}^{n}\left(\lg H_{i}-\overline{\lg H}\right)^{2}\right]^{\frac{1}{2}}
$$

where $d_{n}$ is a parameter determined based on the number of measurements; $H_{i}$ is the hardness parameter based on the $i$ th measurement; $\overline{\lg H}$ is the mean hardness calculated based on the results of $n$ measurements $(n=20-30)$. Since the stability of hardness characteristics obtained in mass tests largely depends on the homogeneity of the material structure, then the greater the heterogeneity of the material structure, the greater the scatter of the values measured. 
The procedure for using this formula is described in the standard [36]. The authors used this standard to analyse their results but did not perform calculations that went beyond its requirements. In addition, in its focus, the article is phenomenological, not statistical; therefore, the statistical aspects of these studies will be published in a separate publication.

The physical substantiation of this method is as follows: The dispersion of mechanical properties is inherent in all materials and the magnitude of their scatter depends mainly on their structural state. Therefore, depending on the mechanical loading type, the changes in the structural state of the surface layers of structural materials can be assessed by the distribution law parameters that describe this scatter. In other words, the assessment is based on the degree of scatter of mechanical properties.

High values of the homogeneity coefficient correspond to the low scatter level of physical and mechanical properties and, accordingly, to a better organization of the structure. The durability of the structure can be predicted with acceptable reliability by comparing the homogeneity coefficient $m_{i}$ calculated from hardness characteristics at different stages of loading the specimen from the structural material. We can also load the structure itself, provided it has the initial value of homogeneity coefficient $m_{\text {init }}$. Knowing or predicting limiting values of $m_{\text {lim }}$ under a certain type of loading is also helpful.

Based on the above provisions proposed by Y. Murakami and A.O. Lebedev, determining the endurance limit of materials based on the initial hardness of the materials and assessing the damage of the surface layers of the materials by the scatter of hardness $m$ in the process of deformation, the authors proposed physical and mechanical models that combine the above approaches to quantify the cycles to fracture of the investigated aluminum alloys at given conditions of variable loading. An attempt was also made to adapt these models to estimating the effect of previous dynamic non-equilibrium processes caused by impact-oscillatory loading on the number of cycles to fracture of alloys upon subsequent cyclic loading.

The relative critical values of hardness scatter under the variable cyclic loadings studied $\left(m_{e}\right)$ were determined on fractured specimens in the transverse direction in areas close to the fracture surface. A similar technique was then used for all specimens fractured under cyclic loading preceded by the realization of DNPs of different intensities.

\subsection{Materials and Specimen for Test}

The mechanical properties and chemical composition of aluminum alloys studied are presented in Tables 1 and 2. Table 1 shows the average values of the mechanical properties and chemical composition of sheets from one industrial delivery. The dispersion of the mechanical properties was not determined, since the article has a phenomenological scientific direction.

Table 1. Mechanical properties of the aluminum alloys studied.

\begin{tabular}{ccccc}
\hline Alloys & $\mathbf{E}(\mathbf{M P a})$ & $\sigma_{y s}(\mathbf{M P a})$ & $\sigma_{u s}(\mathbf{M P a})$ & $\delta(\%)$ \\
\hline 2024-T351 & $0.72 \cdot 10^{5}$ & 342 & 462 & 20.5 \\
D16 ChATW & $0.71 \cdot 10^{5}$ & 322 & 452 & 21.5 \\
\hline
\end{tabular}

Table 2. Chemical composition of the aluminum alloys studied.

\begin{tabular}{cccccccc}
\hline \multicolumn{7}{c}{ Alloy 2024-T351 (\%) } \\
\hline Si & Fe & Cu & Mn & Mg & $\mathbf{C r}$ & Zn & Ti \\
0.05 & 0.13 & 4.7 & 0.70 & 1.5 & 0.01 & 0.02 & 0.04 \\
\hline \multicolumn{7}{c}{ Alloy D16ChATW (\%) } \\
\hline Si & Fe & $\mathbf{C u}$ & Mn & Mg & $\mathbf{C r}$ & Zn & Ti \\
0.11 & 0.18 & 4.4 & 0.63 & 1.4 & 0.01 & 0.01 & 0.07 \\
\hline
\end{tabular}


The test specimens are given in Figure 1. These specimens have a specific shape, because the standard specimens with a localized cross section used in fatigue tests are not suitable for these studies, as they cannot reliably estimate the intensity of introducing impulse energy into the alloy (IOL) using the technique developed by the authors [37-40]. This is a fundamental point, because, depending on the intensity of introducing impulse energy, the structure of aluminum alloys changes dramatically, which is reflected in the mechanical characteristics under the following different types of loading [12-14]. Only by using flat specimens it is possible to obtain a uniform, newly created dissipative structure throughout the working part of the specimen at a given intensity of introducing impulse energy. In addition, the proposed simp parameter makes it possible to estimate the effect caused by the intensity. The specimens of each material were made from one sheet $3 \mathrm{~mm}$ thick.

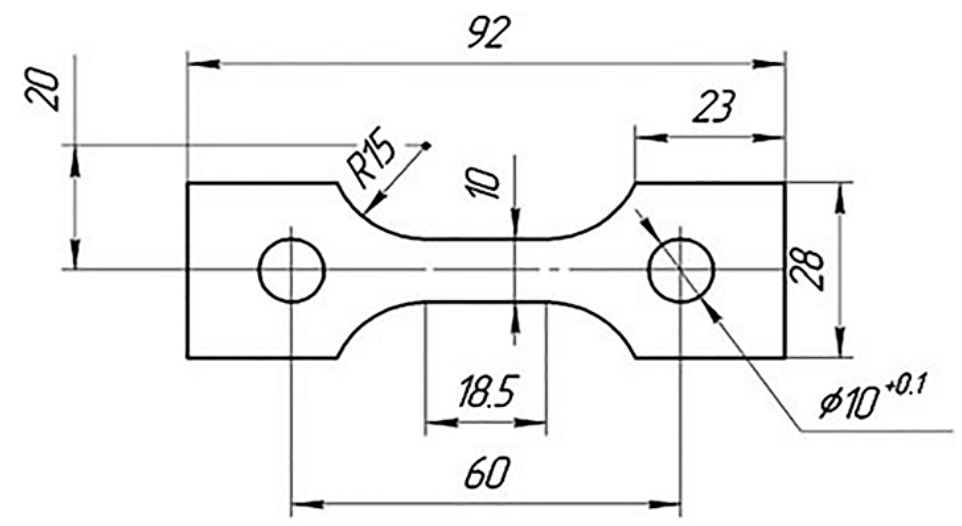

Figure 1. Test specimen (in $\mathrm{mm}$ ).

\section{Analysis of Experimental Results of Fatigue Testing in the Initial State}

Figure 2 presents the experimental data on estimating the fatigue life of alloys D16ChATW and 2024-T351 [13,14] in the initial state.

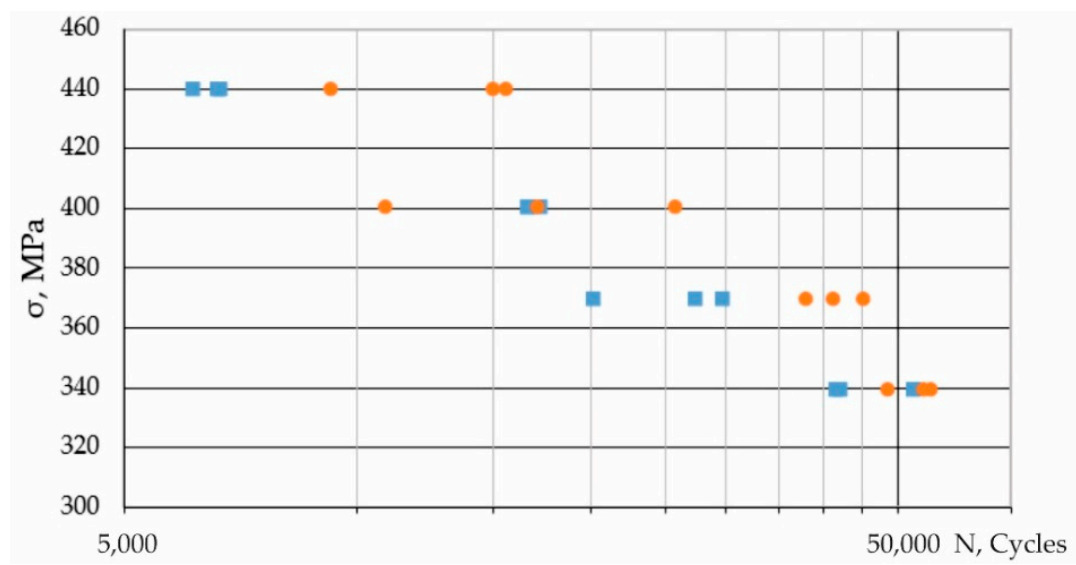

Figure 2. Fatigue testing of aluminum alloys in the initial state at variable cyclic loads: $\mathbf{m}$, cycles to failure (D16ChATW); $\bullet$, cycles to failure (2024-T351). Data from [13,14].

For each maximum cycle stress, three specimens from the investigated alloys were tested. The analysis of the fatigue results obtained shows that, with an insignificant variation of the chemical composition and mechanical properties of the alloys upon static tensioning, the investigated alloys differ appreciably in fatigue test results (Figure 2). This may be due to a special polymer film formed on alloy 2024-T351.

Particularly noteworthy is that, under certain conditions of variable loading (see Figure 2), the number of cycles to fracture of alloy 2024-T351 in the initial state is almost 2.2 times as high as that of alloy D16ChATW. On the other hand, there is a significant scatter of experimental data on alloy 2024-T351 at high cycle stresses. In general, the test results 
for alloy D16ChATW obey the linear law. At the same time, when testing alloy 2024-T361, the effect of high and low cycle stresses on the number of cycles to failure is clearly visible.

\subsection{Physical-Mechanical Models for Predicting the Fatigue Life of Aluminum Alloys in the} Initial State

As already noted, the LM method for estimating damage to the surface layers of the material is based on determining the homogeneity coefficient $m$ [36]. In addition, this estimation can be performed using the absolute values of the homogeneity coefficient $m$ at any stage of operation or deformation of the structural material under any loading type, or using the relative values of the homogeneity coefficient $m_{e}$ when the current value of the homogeneity coefficient $m_{i}$ refers to the original $m_{\text {init }}$.

Based on the experimental results of estimating the number of cycles to failure of aluminum alloys D16ChATW and 2024-T351 in the initial state, the authors proposed and tested a physical and mechanical model for predicting the fatigue life of each alloy investigated. The basic parameters of the model include alloy hardness in the initial state, yield strength of the alloy in the initial state, relative critical values of hardness scatter under variable cyclic $m_{e}$ and two coefficients, $C_{1}$ and $C_{2}$, which are determined based on the results of experimental studies with the minimum number of pre-set variable loading conditions.

The main version of this model for alloy D16ChATW has the following form:

$$
N_{\text {cycles }}=C_{1} \cdot \frac{H V}{\sigma_{y s}} \cdot m_{e}+C_{2}
$$

where $C_{1}=-1.39 \times 10^{7} ; C_{2}=1.04 \times 10^{5} ; H V=2.84 \mathrm{MPa} ; \sigma_{y s}=328.4 \mathrm{MPa}$.

Accordingly, for alloy 2024-T351, we obtain:

$$
N_{\text {cycles }}=C_{1} \cdot \frac{H V}{\sigma_{y s}} \cdot m_{e}^{3}+C_{2} \cdot m_{e}
$$

where $C_{1}=-6.89 \times 10^{7} ; C_{2}=2.33 \times 10^{5} ; H V=2.67 \mathrm{MPa} ; \sigma_{y s}=348.7 \mathrm{MPa}$.

Figure 3 shows a comparison of experimental results relating to the number of cycles to failure of alloys D16ChATW and 2024-T351 at given variable loading conditions with the analytical results of the structural-mechanical models proposed in (Equations (3) and (4)). A good agreement between the results is obvious.

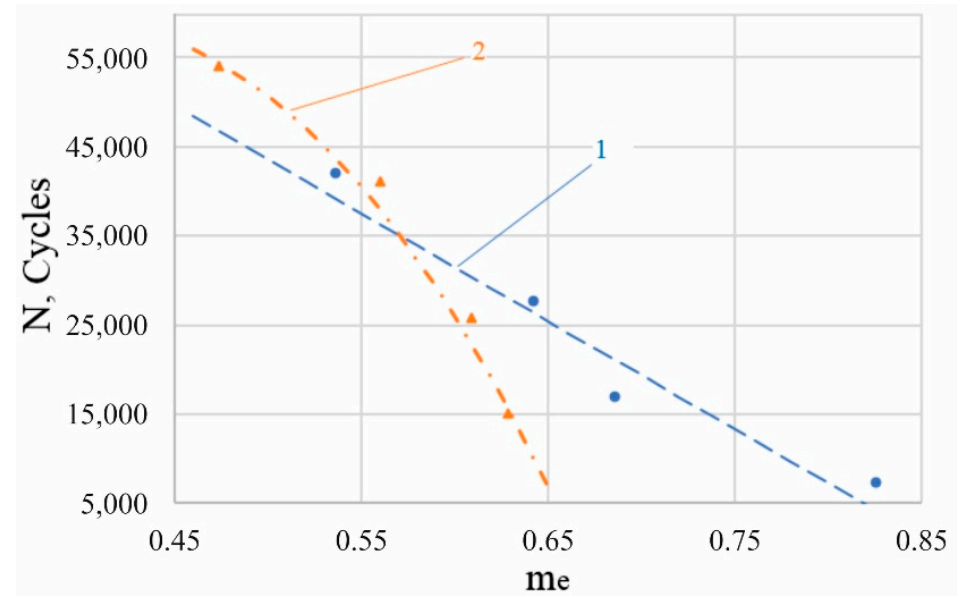

Figure 3. Comparison of experimental results on the number of cycles to failure of aluminum alloys in the initial state (D16ChATW (blue dots); 2024-T351 (red triangles)) at given variable loading conditions $\left(m_{e}\right.$ parameter) with analytical results of the structural and mechanical models proposed (dashed line 1, Equation (3); dashed curve 2, Equation (4)). 
The obtained Equations (3) and (4) can be successfully used to estimate the number of cycles to failure of aluminum alloys at any given cyclic loading conditions (at any given $\left.\sigma_{\max }\right)$. For this purpose, it is enough to plot a $\sigma_{\max }$ versus $m_{e}$ graph with the minimum number of pre-set variables loading conditions. The article does not propose a prediction method based on a probabilistic approach, estimates of probability, errors, etc. We developed a deterministic, engineering approach to assessing the conditions of the materials.

Figure 4 shows an example of such dependence for alloy D16ChATW and the corresponding analytical approximation (Equation (5)).

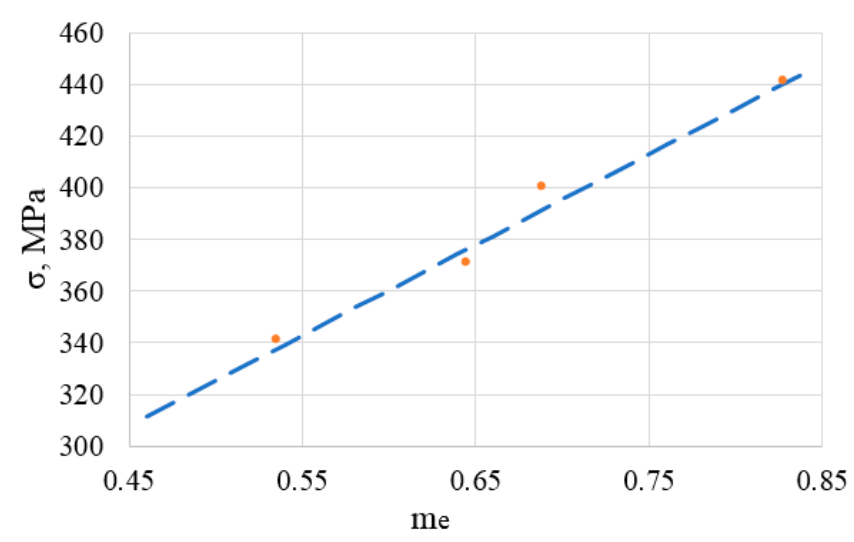

Figure 4. $\sigma_{\max }$ versus $m_{e}$ graph for alloy D16ChATW taking into account cyclic deformation conditions realized.

$$
\sigma_{\max }=350.6 \cdot m_{b}+150
$$

Next, by setting any specific $\sigma_{\max }$ value, we determine the corresponding $m_{e}$ value by Equation (5) or the graph shown in Figure 4 and, substituting it in Equation (3), we obtain the required number of cycles to fracture $N_{\text {cycle }}$ of the alloy.

3.2. Physical-Mechanical Model for Predicting Fatigue Life of Aluminum Alloy after Preliminary Introduction of Impulse Energy of Optimal Intensity

To adapt the proposed structural-mechanical model to estimating the effect of dynamic non-equilibrium processes caused by impact-oscillatory loading on the number of cycles to fracture of alloys, a detailed analysis of the experimental data on alloy D16ChATW was conducted, along with a number of additional studies on this alloy. The experimental data for alloy D16ChATW obtained at three intensities of introducing impulse energy under a DNP at $\varepsilon_{i m p}=3.7 \%, 5.4 \%$ and $7.7 \%$ cover the entire range of maximum cycle stresses under the cyclic deformation studied [13]. Unfortunately, the previous experimental data for alloy 2024-T351 taking into account the influence of the DNP at the low values of $\varepsilon_{\text {imp }}=1.5 \%$ and $5.0 \%$, at which the maximum increase in the number of cycles to fracture of the alloy was attained in subsequent cyclic tests, do not cover the entire range of maximum cycle stresses [14]. Therefore, in later experiments, the authors limited themselves to the analysis of the data obtained for alloy D16ChATW only.

Figure 5 shows the results on the effect of the maximum cycle stresses of the alloy in the initial state and after applying three different additional impulse loads on the number of cycles to failure. The effect of high and low cycle stresses on the number of cycles to fracture of alloy D16 subjected to DNP has a number of features, which were revealed (see Figure 5). As noted earlier, for alloy D16ChATW in the initial state, an almost linear dependence of the number of cycles to failure on the maximum cycle stress was obtained. At the same time, as seen from Figure 5, at $\varepsilon_{i m p}=3.7 \%$ and $5.4 \%$ (see Figure $5 \mathrm{a}, \mathrm{b}$ ), the DNP is represented by inflections on the curves at the maximum cycle stress $\sigma_{\max }=400 \mathrm{MPa}$. It is noteworthy that $\sigma_{\max }=400 \mathrm{MPa}$ practically corresponds to the new yield strength of alloy D16ChAT subjected to the DNP of different intensities followed by static tension [13]. It was found that, with $\varepsilon_{i m p}=3.7 \%$ at the three cycle stresses $\sigma_{\max }=400 \mathrm{MPa}, 370 \mathrm{MPa}$ 
and $340 \mathrm{MPa}$, the fatigue life of the alloy improves and, at $\sigma_{\max }=440 \mathrm{MPa}$, a positive effect is not achieved (see Figure 5a). Similarly, with $\varepsilon_{i m p}=5.4 \%$ at the two cycle stresses $\sigma_{\max }=440 \mathrm{MPa}$ and $400 \mathrm{MPa}$, the fatigue life of the alloy either improves or does not change, compared to the initial state (see Figure $5 b$ ). However, at the low cycle stresses $\sigma_{\max }=370 \mathrm{MPa}$ and $340 \mathrm{MPa}$, the fatigue life of the alloy decreases (see Figure 5b). With high values of $\varepsilon_{i m p}=7.7 \%$, the fatigue life of the alloy decreases at almost all values of $\sigma_{\max }$ (see Figure 5c). Moreover, the inflection on the curve occurred at $\sigma_{\max }=370 \mathrm{MPa}$. The regularities found in the effect of DNP on the fatigue life of alloy D16ChATW clearly indicate specific changes in the structural state of alloy surface layers, as well as in the volume of the material, depending on the intensity of impulse energy introduced into the alloy. Since after impulse loading of different intensity we are dealing with completely different physical and mechanical properties of the aluminum alloy compared to the initial state, then, in the process of subsequent cyclic loading with different maximum stresses of the cycle, we can expect significant changes in the curve showing the scatter of alloy hardness $m$ or its relative values $m_{e}$.

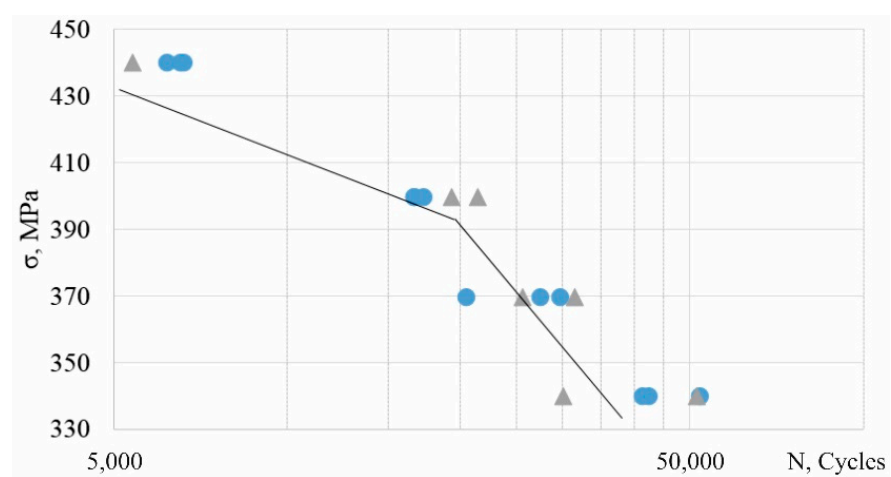

(a)

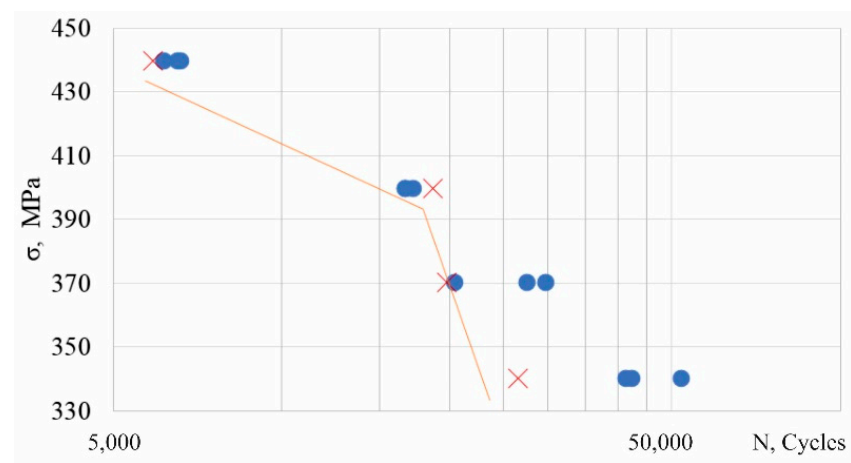

(b)

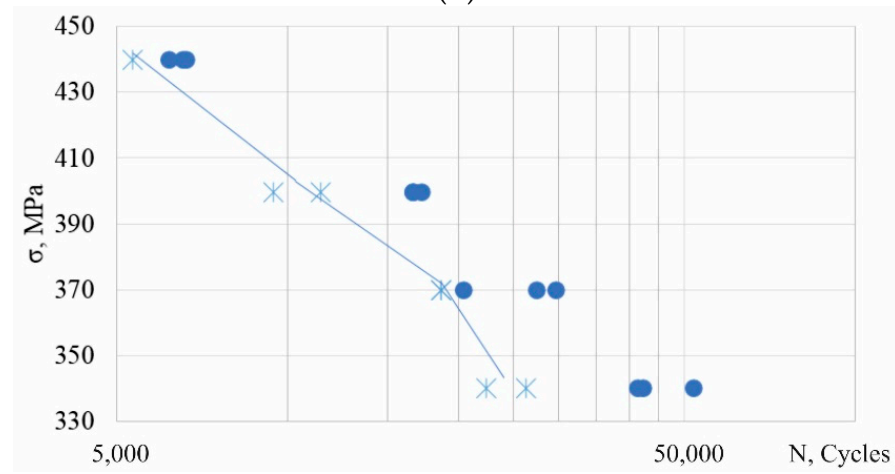

(c)

Figure 5. Cyclic durability of alloy D16ChATW in the initial state ( $)$ and after DNP: (a) $\operatorname{\varepsilon imp}=3.7 \%(\Delta) ;(\mathbf{b}) \varepsilon \operatorname{imp}=5.4 \%(\times)$; (c) $\operatorname{\varepsilon imp}=7.7 \%(\nVdash)$. 
To present the revealed features of changes in cyclic durability depending on the DNP, the authors conducted additional studies on certain specimens from alloy D16ChAT (Figure 6; specimens on which hardness was measured and marked with a ring and squares), which were tested at the maximum cycle stress $\sigma_{\max }=400 \mathrm{MPa}$ to estimate changes in the relative hardness values $H V_{\mathrm{e}}$ and relative scattering parameters $m_{e}$, depending on the intensity of the impulse energy introduction. For clarity, the data are presented in the following form (Figure 7).

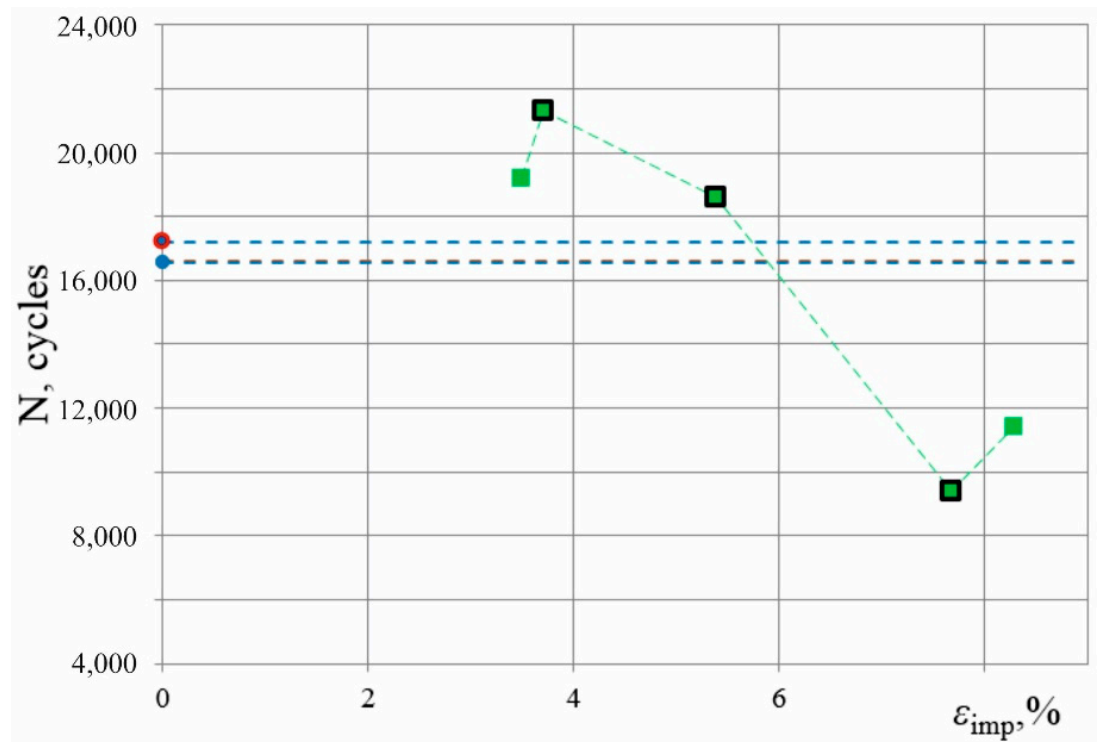

Figure 6. The effect of the intensity of the impulse energy introduction on the number of cycles to fracture of alloy D16ChATW $\left(\sigma_{\max }=400 \mathrm{MPa}\right)$ : $\square$ indicates the alloy condition after the DNP and exposure for 6-7 months; $\mathbf{\square}$ indicates the initial state of the alloy; blue lines indicate data scatter in the initial state date form [13].

The analysis of the results presented in Figure 7 indicates that, at sudden impulse loads of different intensity (DNP), which are associated with a significant change in the phase and structural condition of the surface layers of the alloy, the pattern of the changes in the limit values of the relative parameter $m_{e}$ is very complex. Moreover, it should be noted that the nature of the changes in the relative parameter $\mathrm{HV}_{\mathrm{e}}$, depending on the intensity of the impulse energy introduction by parameter $\varepsilon_{i m p}$, is also very complex.

A deep physical interpretation of this tendency (see Figure 7) requires additional research; the authors understand its physical essence as follows: DNPs of different intensities affect the change in the chemical composition of the surface. In this case, the hardness of the surface of the alloys after the DNP increases, but the number of brittle phases in it also increases, which increases the scattering of the results. This interpretation is consistent with the data presented in $[13,14]$.

Thus, it turns out that predicting the fatigue life of the alloy by the structural parameter $m_{e}$ during the realization of DNPs of different intensities in aluminum alloys is problematic at this stage of research [40]. Even when trying to predict the number of cycles to failure by the relative values of the limiting parameters $m_{e}$ for the data shown in Figure 7, there are many difficulties (see Figure 8). 


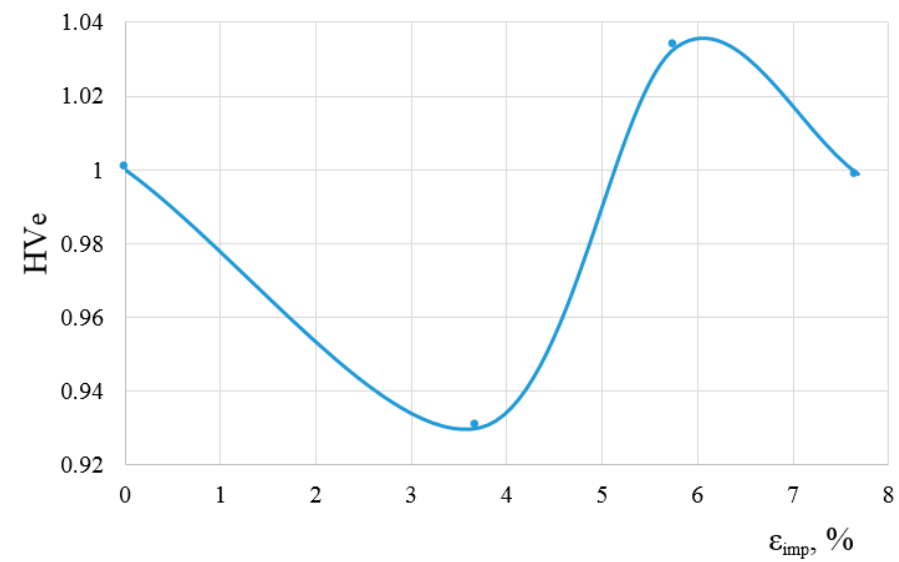

(a)

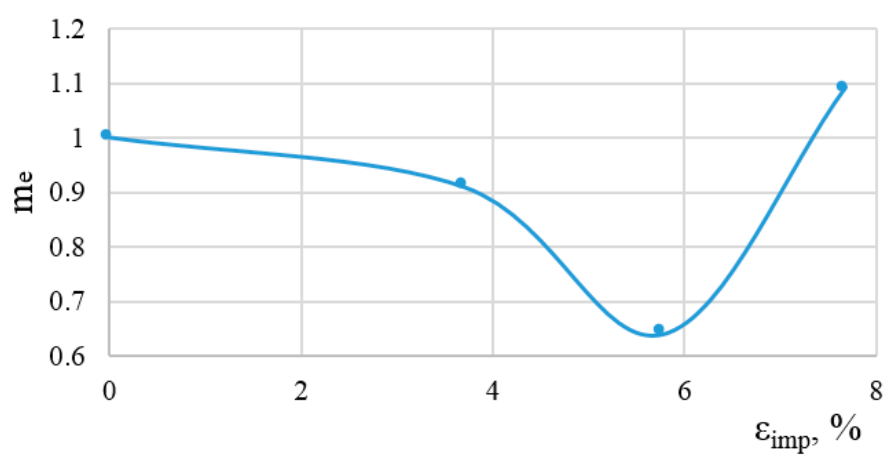

(b)

Figure 7. The effect of the intensity of the impulse energy introduction into alloy D16ChATW depending on parameter $\varepsilon_{i m p}$, which causes changes in the relative value of parameter $H V_{\mathrm{e}}(\mathbf{a})$ and relative value of parameter $\mathrm{m}_{\mathrm{e}}(\mathbf{b})$ (maximum cycle stress $\sigma_{\max }=400 \mathrm{MPa}$ ).

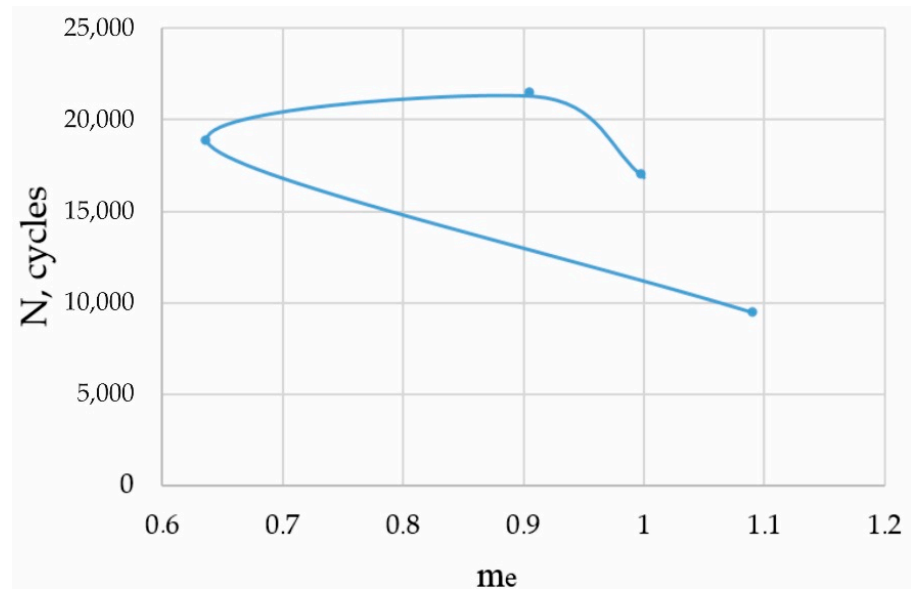

Figure 8. Dependence of cycles to fracture of alloy D16ChATW at different intensities of additional impulse loading applied $\left(\varepsilon_{i m p}=3.7 \%, 5.4 \%\right.$ and $\left.7.7 \%\right)$ and in the initial state on the limiting values of $m_{e}$ (maximum cycle stress $\sigma_{\max }=400 \mathrm{MPa}$ ).

Figure 9 shows the results of the comparison of the cyclic durability of alloy D16ChATW in the initial state and after the DNP $\left(\varepsilon_{i m p}=3.7 \%, 5.4 \%\right.$ and $\left.7.7 \%\right)$ with the experimental values of the limiting relative parameters $m$. It should be noted that, in this case, the critical values of parameter $m$ were selected as a damage parameter of the surface layers of the alloy. As shown in standard [36], it is allowed to choose either parameter $m_{e}$ or parameter $m$ for a specific type of loading. 


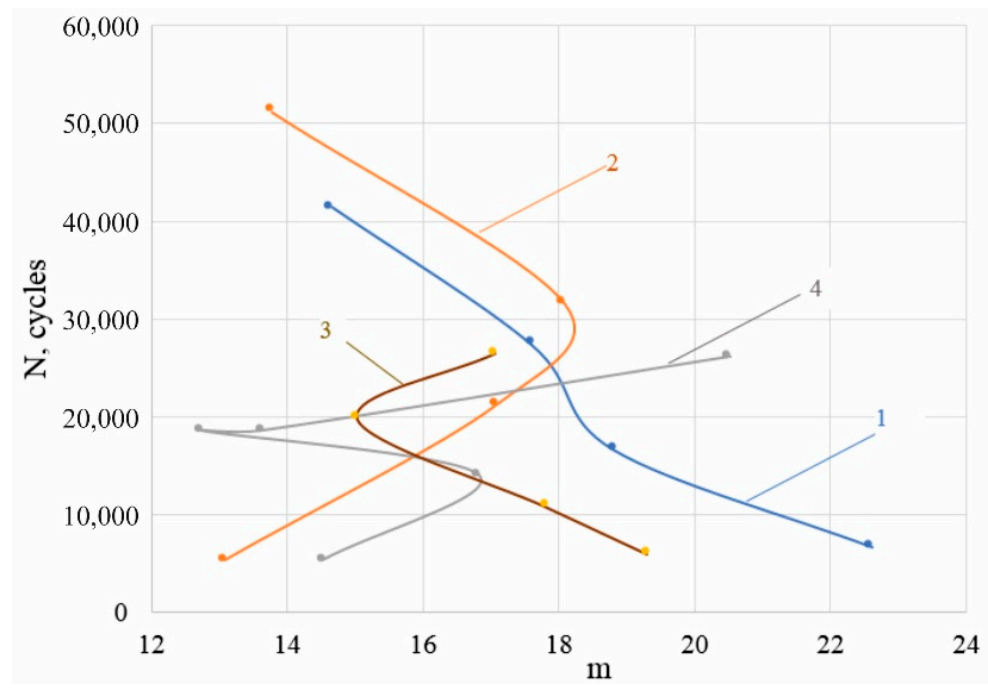

Figure 9. Results of experimental comparison of the number of cycles to fracture of alloy D16ChATW in the initial state and after DNPs of different intensities with the experimental values of limiting parameters $m$ : 1 , initial state; $2, \varepsilon_{i m p}=3.7 \% ; 3, \varepsilon_{i m p}=5.4 \% ; 4, \varepsilon_{i m p}=7.7 \%$ at all variable cyclic loading conditions investigated $\left(\sigma_{\max }=340,370,400\right.$ and $\left.440 \mathrm{MPa}\right)$.

The analysis of Figure 9 shows a very complex nature of the established dependencies. Moreover, the greater the intensity of the DNP, the more complex is the nature of the dependencies. Note curve 4 in Figure 9.

Despite a fairly complex nature of the regularities found (see Figure 10), the authors made an attempt to adapt the proposed version of the structural and mechanical model (Formula 3) to predicting the number of cycles to fracture in case of a preliminary realization of DNP in the alloy at $\varepsilon_{i m p}=3.7 \%$ (intensity of introducing impulse energy). The previous realization of DNP in the alloy is most helpful in increasing the number of cycles to fracture under subsequent cyclic loading (see Figure $5 \mathrm{a}$ ). To this end, an additional $C_{3}$ coefficient was introduced into the structural and mechanical model.

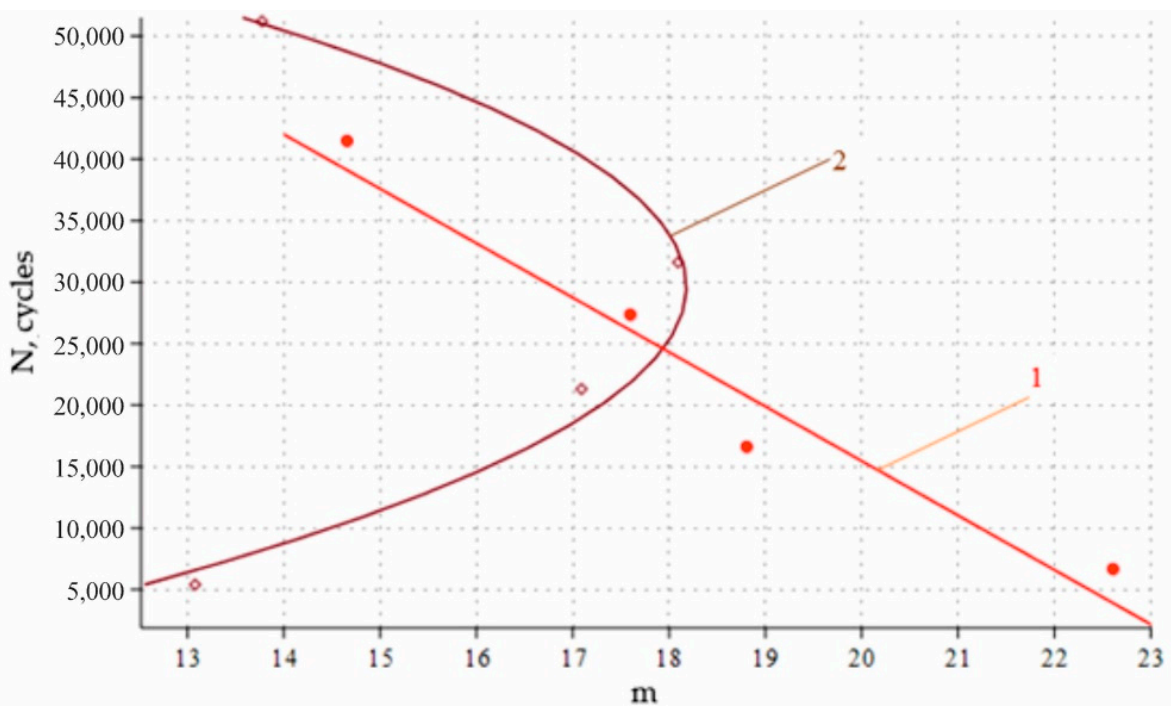

Figure 10. Comparison of experimental results on the number of cycles to fracture of aluminum alloy D16ChATW in the initial state (red dots) and after introducing impulse energy $\varepsilon_{i m p}=3.7 \%$ into the alloy (brown characters) at specified conditions of variable loading with analytical results obtained using the proposed structural and mechanical models (line 1, Equation (3); line 2, Equation (6)). 
As a result, we have the following version of the structural and mechanical model:

$$
\left(N_{\text {cycles }}-C_{1}\right)^{2}=2 \cdot C_{2} \cdot \frac{H V}{\sigma_{y s}} \cdot\left(m-C_{3}\right)
$$

where $C_{1}=2.96 \times 10^{4} ; C_{2}=1.86 \times 10^{10} ; C_{3}=18.18 ; H V=2.84 \mathrm{MPa} ; \sigma_{y s}=448.7 \mathrm{MPa}$. In this case, a new yield strength of the alloy after the realization of DNP is substituted in Equation (6) [13].

The comparison of the calculations made in accordance with Equation (6) with experimental results shows a good agreement (see Figure 10).

\section{Discussion}

The complexity of the experimental studies conducted allowed us to identify a number of interesting features in predicting the fatigue life of aluminum alloys. Particularly noteworthy is that earlier predictions of fatigue life of aluminum alloys practically disregarded the fact that, in the process of cyclic loading, the structural material may be subjected to additional impulse loads of different intensity. As a result, a short-term dynamic chaos may occur in mechanical systems or, in other words, DNP may be realized in the materials of the systems. Consequently, the structure and phase composition of surface layers and in the volume of materials change radically $[13,14,41]$. That is, as shown by the results of experimental studies, it appears that, when the phase composition of alloys does not change in the process of cyclic loading and, accordingly, the physical and mechanical properties of the surface layers of alloys remain unchanged, then the $m_{e}$ and $m$ parameters can be used as basic parameters in structural and mechanical models for estimating the number of cycles to fracture. In this case, this refers to the investigated alloys in the initial state. When, by virtue of sudden additional impulse loads, DNPs are realized in the process of cyclic loading of the structural material, the previous dependences of the number of load cycles on the relative or absolute values of $m_{e}$ and $m$ change dramatically. This is because the phase composition in the surface layers of alloys changes radically, along with the physical and mechanical properties of the surface layers of the alloys. Therefore, with further cyclic loading, we have a completely different dependence of the number of cycles to fracture of alloys on the relative values of the $m_{e}$ parameters or absolute values of the $m$ parameters. Moreover, it turned out that maximum cycle stresses of the subsequent cyclic loading have the greatest effect on the changes in dependence of the number of cycles to fracture of alloys on the relative values of the $m_{e}$ parameters or absolute values of the $m$ parameters after the realization of the DNP.

According to the authors, this is one of the possible reasons for such a complex nature of the changes in the boundary values of the relative parameter $m$ in case of impulse introduction of energy of different intensities (see Figure 9), since high and low values of maximum cycle stresses at variable loading differently affect the scatter of hardness values in the surface layers of aluminum alloys after the realization of the DNP. As shown earlier, dissipative structures of less density, which are created in the realization of the DNP, are extruded on the specimen surface $[40,41]$. Thus, a hybrid structure with alternating soft (dissipative structure) and solid zones (the main material) is created in the surface layers of alloys. Accordingly, at low values of maximum load cycle stresses (below the new yield strength of the alloy), both soft and solid zones are deformed in an elastic region; therefore, no noticeable changes are recorded in the nature of the curve showing the parameter $m$ under cyclic loading with different maximum cycle stresses. At high cycle stresses (above the new yield strength of the alloy), soft zones (dissipative structure) are the first to actively deform in the surface layers of the alloy. As a result, the scatter of the physical-mechanical properties of the alloy in the surface layers of the alloy increases and, accordingly, the coefficient of homogeneity $m$ decreases. That is, the organization of the structure in the surface layers is deteriorating. The analysis of Figure 9 shows that, depending on the intensity of introducing impulse energy by the parameter $\varepsilon_{i m p}$ with the same value $m$, we can obtain two or even three values of the number of cycles to fracture. Thus, using the 
parameters $m$ or $m_{\mathrm{e}}$ in the author-proposed structural and mechanical models for predicting the number of cycles to fracture of aluminum alloys after the realization of DNP becomes problematic. Since earlier models for predicting fatigue life similar to those proposed by Murakami Y. have never been tested under the realization of DNPs in materials, significant changes can be expected in the damage accumulation patterns that occur in the surface layers of alloys after the realization of DNPs of different intensities-one of the main parameters of the model proposed by Murakami Y.

\section{Conclusions}

Physical and mechanical models for predicting the fatigue life of aluminum alloys D16ChATW and 2024-T351 are proposed for the first time. The initial alloy hardness $H V$ and limiting scatter of alloy hardness $m$ in the process of cyclic loading at fixed maximum cycle stresses, or their relative values $m_{e}$ are the main model parameters. The models were tested under specified conditions of variable loading at maximum cycle stresses $\sigma_{\max }=340-440 \mathrm{MPa}$, approximate load frequency of $110 \mathrm{~Hz}$ and cycle asymmetry coefficient $R=0.1$ on specimens from alloys in the initial state and after the realization of DNPs at $\varepsilon_{i m p}=3.7 \%, 5.4 \%$ and $7.7 \%$.

It is shown that, when the phase composition of the surface layers does not change in the process of cyclic loading, this refers to specimens in the initial state. In this case, the proposed physical and mechanical models are in good agreement with the experimental data. When the phase composition of surface layers varies significantly in the process of previous realization of DNPs of different intensities and, accordingly, the physical and mechanical properties of surface layers change significantly, then predicting the fatigue life of alloys under further cyclic loading in accordance with the proposed models becomes problematic. Thus, any additional impulse loads applied to the structural material during the main cyclic loading lead to drastic changes in the damage accumulation patterns that occur in the surface layers of aluminum alloys. This fact must be taken into account when developing new models for predicting the fatigue life of aluminum alloys of such classes.

Author Contributions: Conceptualization, M.C. and P.M.; methodology, A.P. and A.M.; analysis and validation, M.C., P.M., A.P., A.M.; writing, M.C., P.M. and A.P.; review and editing, M.C., A.M.; supervision, P.M. All authors have read and agreed to the published version of the manuscript.

Funding: This research received no external funding.

Institutional Review Board Statement: Not applicable.

Informed Consent Statement: Not applicable.

Data Availability Statement: The data presented in this study are available on request from the corresponding author.

Conflicts of Interest: The authors declare no conflict of interest.

\section{References}

1. Sakin, R. Investigation of bending fatigue-life of aluminum sheets based on rolling direction. Alex. Eng. J. 2018, 57, 35-47. [CrossRef]

2. Kim, S.; Frangopol, D.M. Multi-objective probabilistic optimum monitoring planning considering fatigue damage detection, maintenance, reliability, service life and cost. Struct. Multidisc. Optim. 2018, 57, 39-54. [CrossRef]

3. Aboulkhair, N.T.; Maskery, I.; Tuck, C.; Ashcroft, I.; Everitt, N.M. Improving the fatigue behaviour of a selectively laser melted aluminium alloy: Influence of heat treatment and surface quality. Mater. Des. 2016, 104, 174-182. [CrossRef]

4. Zhang, Q.; Zhu, Y.; Gao, X.; Wu, Y.; Hutchinson, C. Training high-strength aluminum alloys to withstand fatigue. Nat. Commun. 2020, 11, 5198. [CrossRef] [PubMed]

5. Ueno, A.; Miyakawa, S.; Yamada, K.; Sugiyama, T. Fatigue behavior of die casting aluminum alloys in air and vacuum. Procedia Eng. 2010, 2, 1937-1943. [CrossRef]

6. Khonsari, M.M.; Amiri, M. Introduction to Thermodynamics of Mechanical Fatigue, 1st ed.; CRC Press: Boca Raton, FL, USA, 2012; 166p. [CrossRef]

7. Brodova, I.G.; Petrova, A.N.; Razorenov, S.V.; Shorokhov, E.V. Interconnection of structural characteristics with dynamic properties of A5083 aluminum alloy. Inorg. Mater. Appl. Res. 2019, 10, 168-173. [CrossRef] 
8. Borodin, E.N.; Bratov, V. Non-equilibrium approach to prediction of microstructure evolution for metals undergoing severe plastic deformation. Mater. Charact. 2018, 141, 267-278. [CrossRef]

9. Kaibyshev, O.; Valiev, R. Non-equilibrium structure of grain boundaries and properties of metals. J. Phys. Coll. 1985, 46, C4-641-C4-644. [CrossRef]

10. Nazarov, A.A. On the role of non-equilibrium grain-boundary structure in the yield and flow stress of polycrystals. Philos. Mag. A 1994, 69, 327-340. [CrossRef]

11. Hutsaylyuk, V. The peculiarity of cyclic elastic-plastic deformation of aluminum alloys D16ChATV under the conditions of the previous combined load. Mech. Adv. Mater. Struct. 2020, 27, 1246-1255. [CrossRef]

12. Chausov, M.; Brezinová, J.; Pylypenko, A.; Maruschak, P.; Titova, L.; Guzanová, A. Modification of mechanical properties of high-strength titanium alloys VT23 and VT23M due to impact-oscillatory loading. Metals 2019, 9, 80. [CrossRef]

13. Chausov, M.; Brezinova, J.; Zasimchuk, E.; Maruschak, P.; Khyzhun, O.; Pylypenko, A.; Bazarnik, P.; Brezina, J. Effect of structure self-organization of aluminum alloy D16ChATW under impact-oscillatory loading on its fatigue life. J. Mater. Eng. Perform. 2021, 30, 6235-6242. [CrossRef]

14. Chausov, M.; Zasimchuk, E.; Maruschak, P.; Khyzhun, O.; Pylypenko, A.; Prentkovskis, O.; Brezinová, J. Influence of impactoscillatory loading on fatigue life of aluminium alloy 2024-T351. Iran. J. Sci. Technol. Trans. Mech. Eng. 2021. [CrossRef]

15. Shankar, M.R.; Chandrasekar, S.; Compton, W.D.; King, A.H. Characteristics of aluminum 6061-T6 deformed to large plastic strains by machining. Mater. Sci. Eng. 2005, 410-411, 364-368. [CrossRef]

16. Kwon, K.; Frangopol, D.M. Fatigue life assessment and lifetime management of aluminum ships using life-cycle optimization. J. Ship Res. 2012, 56, 91-105. [CrossRef]

17. Gao, Y.X.; Yi, J.Z.; Lee, P.D.; Lindley, T.C. A micro-cell model of the effect of microstructure and defects on fatigue resistance in cast aluminum alloys. Acta Mater. 2004, 52, 5435-5449. [CrossRef]

18. Ignatovich, S.R.; Menou, A.; Karuskevich, M.V.; Maruschak, P.O. Fatigue damage and sensor development for aircraft structural health monitoring. Theor. Appl. Fracture Mech. 2013, 65, 23-27. [CrossRef]

19. Zhu, D.; Xu, L.; Wang, F.; Liu, T.; Lu, K. Evolution of metal surface topography during fatigue. Metals 2017, 7, 66. [CrossRef]

20. Wang, L.; Limodin, N.; El Bartali, A.; Charkaluk, E. Coupling of X-ray computed tomography and surface in situ analysis combined with digital image correlation method to study low cycle fatigue damage micromechanisms in lost foam casting A319 alloy. Fatigue Fracture Eng. Mater. Struct. 2021, 44, 916-932. [CrossRef]

21. Leng, L.; Zhang, Z.J.; Duan, Q.Q.; Zhang, P.; Zhang, Z.F. Improving the fatigue strength of 7075 alloy through aging. Mater. Sci. Eng. A 2018, 738, 24-30. [CrossRef]

22. Maruschak, P.; Konovalenko, I.; Karuskevich, M.; Gliha, V.; Vuherer, T. Automated diagnostics of damage to an aluminum alloy under the conditions of high-cycle fatigue. Mater. Tehnol. 2013, 47, 357-361.

23. Nykyforchyn, H.M.; Ostash, O.P.; Tsyrul'nyk, O.T.; Andreiko, I.M.; Holovatyuk, Y.V. Electrochemical evaluation of the in-service degradation of an aircraft aluminum alloy. Mater. Sci. 2008, 44, 254-259. [CrossRef]

24. Ignatovich, S.R.; Karuskevich, M.V.; Yutskevich, S.S. Deformation relief of the surface as a characteristic of fatigue damage of clad aluminum alloys. Part 1. Deformation relief evolution under cyclic loading. Strength Mater. 2020, 52, 707-714. [CrossRef]

25. Panin, V.E.; Surikova, N.S.; Elsukova, T.F.; Egorushkin, V.E.; Pochivalov, Y. Nanostructured phase boundaries in aluminum under severe cyclic plastic deformation. Phys. Mesomech. 2010, 13, 103-112. [CrossRef]

26. Karuskevich, M.; Ignatovich, S.; Karuskevich, O.; Maslak, T.; Pejkowski, Ł.; Kurdel, P. Fatigue and overstress indicators for ultralight and light aircraft. Fatigue Fracture Eng. Mater. Struct. 2021, 44, 595-598. [CrossRef]

27. Pantelakis, S.G.; Petroyiannis, P.V.; Bouzakis, K.D.; Mirisidis, I. Surface hardness increase of 2024 aluminum alloy subjected to cyclic loading. Theor. Appl. Fracture Mech. 2007, 48, 68-81. [CrossRef]

28. Bouzakis, K.-D.; Mirisidis, I.; Pantelakis, S.G.; Chamos, A.N. Fatigue induced alteration of the superficial strength properties of 2024 aluminum alloy. J. Mater. Sci. Technol. 2011, 27, 776-784. [CrossRef]

29. Murakami, Y. Metal Fatigue: Effects of Small Defects and Nonmetalic Inclusions, 1st ed.; Academic Press: Cambridge, MA, USA, $2002 ;$ p. 384.

30. Murakami, Y. Metal Fatigue: Effects of Small Defects and Nonmetalic Inclusions, 2nd ed.; Academic Press: Cambridge, MA, USA, $2019 ;$ p. 758.

31. Schneller, W.; Leitner, M.; Leuders, S.; Sprauel, J.M.; Grun, F.; Pfeifer, T.; Jantschner, O. Fatigue strength estimation methodology of additively manufactured metallic bulk material. Addit. Manuf. 2021, 39, 101688. [CrossRef]

32. Aigner, R.; Leitner, M.; Stoschka, M. On the mean stress sensitivity of cast aluminium considering imperfections. Mater. Sci. Eng. A 2019, 758, 172-184. [CrossRef]

33. Solberg, K.; Wan, D.; Berto, F. Fatigue assessment of as-built and heat-treated Inconel 718 specimens produced by additive manufacturing including notch effects. Fatigue Fracture Eng. Mater. Struct. 2020, 43, 2326-2336. [CrossRef]

34. Lebedev, A.A.; Muzyka, N.R.; Volchek, N.L. Determination of damage accumulated in structural materials by the parameters of scatter of their hardness characteristics. Strength Mater. 2002, 34, 317-321. [CrossRef]

35. Lebedev, A.; Golubovskiy, Y.; Lokoshchenko, O. Determination of limit levels of damage in materials after operation under conditions of thermomechanical loads. J. Ternopil Natl. Tech. Univ. 2011, 16, 7-14.

36. Novikov, A.; Bulakh, P.; Byalonovich, A. Determination of the Level of Scattered Damage by LM-Hardness Method. Sci. J. Ternopil National Tech. Univ. 2018, 1, 18. 
37. Chausov, N.G.; Voityuk, D.G.; Pilipenko, A.P.; Kuz'menko, A.M. Setup for testing materials with plotting complete stress-strain diagrams. Strength Mater. 2004, 36, 532-537. [CrossRef]

38. Chausov, N.G.; Pilipenko, A.P. Influence of dynamic overloading on fracture kinetics of metals at the final stages of deformation. Mechanika 2004, 48, 13-18.

39. Chausov, M.G.; Berezin, V.B.; Pylypenko, A.P.; Hutsaylyuk, V.B. Strain field evolution on the surface of aluminum sheet alloys exposed to specific impact with oscillation loading. J. Strain. Anal. 2014, 50, 61-62. [CrossRef]

40. Zasimchuk, E.; Turchak, T.; Chausov, N. Hydrodynamic plastic flow in metal materials. Results Mater. 2020, 6, 100090. [CrossRef]

41. Chausov, M.; Maruschak, P.; Zasimchuk, E.; Pylypenko, A.; Bishchak, R.; Burda, I. About Physical Aspects of Increasing Durability of Aluminum Alloys Due to Impact-Oscillatory Loading. In Lecture Notes in Intelligent Transportation and Infrastructure; Springer: Berlin, Germany, 2020; pp. 572-580. [CrossRef] 